\title{
Educação Musical e diversidade cultural: diálogos acerca de uma aprendizagem musical intercultural
}

Leonardo Moraes Batista

Professor Mestre. Conservatório Brasileiro de Música, Rio de Janeiro, RJ.

E-mail: leonardomoraesbatista@gmail.com. 


\section{Resumo}

Esse artigo aborda questões de aprendizagem musical para o campo da escola repensando o campo da educação musical em diálogo com a diversidade cultural e o multiculturalismo intercultural como meio de pensarmos novas epistêmes fora dos cânones orquestrados pelas culturas europeias. Por meio de conceitos do multiculturalismo sobre a voz de Candau $(2008,2012)$ com o auxílio de Queiroz (2011, 2013, 2015) proponho discussão sobre o lugar da educação musical dentro de um propósito da diversidade cultural, com intercâmbios dentro de um contexto democrático acerca do pluralismo cultural. Com as vozes de Oliveira (2008) e Filho (2010) evoco alguns caminhos no intuito de tecer encontros emancipatórios educativos dentro de uma concepção de autonomia, com justiça social e cognitiva, conversa mútua de culturas e reconhecimento com base na pluralidade de ideais em diálogo com a contemporaneidade para um efetivo exercício de uma aprendizagem musical intercultural com diversidade cultural.

Palavras-chave: Projeto educativo emancipatório. Educação musical. Diversidade cultural. Multiculturalismo intercultural.

\section{Abstract}

This article deals with musical learning matters for the field of school, rethinking the field of music education in dialogue with cultural diversity and intercultural multiculturalism as means to come up with new episthemes apart from the canons enacted by European cultures. By the means of multiculturalism concepts about the voice from Candau $(2008,2012)$ and with the help of Queiroz $(2011,2013,2015)$ one brainstorms the position of music education within the purpose of cultural diversity, along with interchanging inside a democratic context from cultural pluralism framework. In the words of Oliveira (2008) and Filho (2010), educational emancipatory encounters are to rethink music education towards conceptual building of autonomy, cognitive and social justice, mutual talk between cultures and recognition, all based on a plurality of ideas in dialogue with contemporaneity, aiming at conceiving was to effective practice of an intercultural musical learning with cultural diversity.

Keywords: Emancipatory educational project. Music education. Cultural diversity. Intercultural multiculturalismo. 
Falar do multiculturalismo é falar do jogo de diferenças, cujas regras são definidas nas lutas sociais por atores que, por uma razão ou outra, experimentaram o gosto amargo da discriminação e dos preconceitos no interior das sociedades em que vivem (GONÇALVES; SILVA, 2013, p. 9).

\section{Introdução}

A Educação Musical escolar diante de processos de reestruturações/redesenhos perpassa cotidianamente por modificações e reconfigurações no seu fazer educacional. Por determinados anos, pedagogicamente constituídos, a Educação Musical brasileira dada pelos processos de ensino e aprendizagem na Educação Básica estiveram pautados sobre proposições eurocêntricas. Proposições estas, que não reconheciam e ainda não reconhecem a ideia de diversidade e pluralidade cultural dos distintos mundos que foram dominados hegemonicamente por muitos anos.

Nos trabalhos de autores que circulam no movimento da Educação Musical do Brasil tais como o de Fonterrada (2008), Queiroz e Mousinho (2009), Pereira (2011) e Figueiredo (2011), apontam o histórico de uma cultura educacional europeizada deslegitimando e excluindo outras proposições pedagógicas musicais. Sinalizam eles que o nosso processo de Educação Musical foi desenvolvido por jesuítas na tal equivocada ideia da descoberta do Brasil.

Diante desse apontamento há de se lembrar de que muitos dos currículos praticados no decorrer do processo de Educação Musical escolar estão pautados sobre proposições de ensino sob propostas pedagógicas de educadores musicais estrangeiros (Dalcroze, Orff, Suzuki, Kodaly, Willems) e brasileiros (Gazzi de Sá, Liddy Mignone, Sá Pereira) do início do século XX que sofreram influências e também tinham suas ideias pedagógicas musicais com contornos dos métodos de cunho eurocêntrico.

Para pautar a problematização/discussão desse texto, lanço alguns questionamentos que poderão nos ajudar a repensar ideias de diversidade e multiculturalismo dentro de um propósito de ampliação do conhecimento musical e emancipação dos cânones que ecoam nas escolas alargando as possiblidades de aprendizagem musical na Educação Básica.

Problematizada a ideia, lanço algumas questões. (a) Temos realmente uma diversidade cultural em nossos currículos e ações didáticas nas proposições pedagógicas 
musicais do dia a dia da sala de aula? (b) Até que ponto, nós docentes contribuímos para uma ação epistemicída ${ }^{1}$ trabalhando cânones de processos de Educação Musical pautados ainda em esquemas europeus? (c) Como a proposição do conceito de multiculturalismo intercultural dentro de uma perspectiva de aprendizagem musical pode oxigenar e reconfigurar ideias pedagógicas musicais que circulam o espaço escolar?

São essas questões que abordarei nesse artigo. Não tenho o intuito de buscar respostas, mas problematizar questões acerca da Diversidade Cultural nos processos de aprendizagem musical no espaço escolar. Juntamente com referenciais teóricos do campo Currículo, do Multiculturalismo Intercultural, da Educação e da Educação Musical, com foco na diversidade cultural. Debaterei questões e pensarei em proposições pedagógicas musicais buscando contribuir para reconsiderações para/com o campo da Educação Musical sem a pretensão de tê-las como palavra final de algo que é uma luta do cotidiano nos distintos espaços educativos.

\section{Algumas ideias sobre a Educação para compor a discussão}

Falar de Educação é falar do humano. É falar de cultura, bem que adquirimos em distintos processos de intercâmbio em diversificadas situações do cotidiano. É falar de experiência com o outro, com o mundo.

Vivemos em um constante furacão de troca de saberes, de conhecimentos e de aprendizagens que, de alguma forma e/ou maneira, ensinamos, compartilhamos e ampliamos o conhecimento de nós mesmos, do outro e do mundo em que vivemos, a partir das relações que se estabelecem na relação do "eu” com o "outro". Ou seja, vivemos em um processo contínuo de intercâmbio.

Acredito que os distintos espaços de ensino poderiam partir dessa premissa de pensamento: educar sem tornar o sentido dessa palavra preso às amarras do fazer por fazer, mas aberto a entender e aceitar que em todos os momentos aprendemos e ensinamos algo a alguém, ao outro.

\footnotetext{
${ }^{1}$ Conceito utilizado pelas Ciências Sociais e Educação. Ver publicações de Boaventura Souza Santos e Inês Barbosa de Oliveira.
} 
Não penso a Educação, o ensino, a aprendizagem, o processo pedagógico, como um amontoado de conteúdos, de objetivos, de justificativas, de avaliações e de processos de ensino e ações que legitimam um projeto tradicionalista de ensino e aprendizagem. Penso o processo pedagógico escolar como prática emancipatória, penso a Educação como "possibilidade de desenvolvimento da autonomia intelectual e social dos sujeitos individuais e coletivos envolvidos no processo educativo" (OLIVEIRA, 2008, p, 101).

Entendo a Educação e processo pedagógico musical que estão inseridos no espaço escolar como uma construção de redes de saberes e conhecimentos múltiplos diante dos propósitos que se integram ao ensino e a aprendizagem de indivíduos que possuem seus desejos, seus valores, suas crenças, suas angústias e seus anseios, e que neste espaço, chamado escola, local de tensões, conflitos e conhecimentos o processo educativo emancipatório pode acontecer. Ou seja, conflitos e tensões dados no dia a dia da sala de aula, podem ser desestabilizados onde "um relacionamento mais igualitário, mais justo que nos faça aprender o mundo de modo edificante, emancipatório e multicultural" (SANTOS, 1996, p. 33 apud OLIVEIRA, 2008, p. 104). Educação como um projeto de diferentes escolhas, caminhos, desejos, anseios e vontades. Como um projeto político, social, cultural, preenchido por pessoas, indivíduos, humanos.

É preciso, também, pensar o novo, reconstruir o velho e reinventar o pensar cotidianamente em nossas ações educativas nos distintos segmentos da Educação Básica como uma ação emancipatória. É imbuir-se de recursos não somente para e por um propósito individual, mas em diálogo com o outro e com o coletivo, aprendendo a fazer diante da rápida transformação do mundo que solicita do indivíduo estar apto a enfrentar novas situações de emprego e a trabalhar em equipe, desenvolvendo espírito cooperativo e com respeito ao outro, na reelaboração conceitual dos paradigmas dominantes repensando sempre quais são os valores necessários para a construção do bojo coletivo.

Creio que não devemos reduzir a palavra Educação a uma sujeita barbárie da instauração do dever, da obrigação, do desconhecer de si, do outro e do mundo. Um projeto educativo emancipatório pode e talvez deva caminhar na esfera do conhecer, do ampliar saberes, do estabelecer novos olhares sobre aquilo que até então não conhecemos, propondo diálogo com o novo, consigo mesmo, com o outro em particularidade com as nuances do mundo em que vivemos. 
A proposta aqui instaurada visa pensar uma pedagogia musical com proposições emancipatórias que se constituam no cerne do processo educativo, como um campo de ação crítica, conflitante e argumentativa que resgate os saberes locais eles individuais e coletivos, dentro de uma perspectiva ética com responsabilidade social e justiça cognitiva daqueles que são responsáveis pelas relações que são estabelecidas no processo de ensino e aprendizagem em educação musical no cotidiano escolar.

\section{Por uma Educação Musical Intercultural nos campos que indivíduos circulam}

Antes de qualquer coisa é importante lembrar que os Movimentos Sociais tem grande potência nessa discussão. Porque nos últimos anos já num período dito PósModerno tem sinalizado e denunciado para a sociedade que muitas dores ainda estão inseridas nas ações que se estabelecem nos cotidianos e ao mesmo tempo estão sendo alimentadas no dia a dia da sala de aula. Em Educação Musical, em alguns estudos tais como de Queiroz (2013, 2015) Del Bem (2013), Resende (2015) têm denunciado os cânones eurocêntricos ainda estabelecidos nas concepções de práxis musical nas escolas de Educação Básica.

As ideias unilaterais e os modelos que se estabeleceram no decorrer dos anos no Brasil diante das abordagens de ensino que mantinham e ainda mantém, em alguns casos, cunho pedagógico com conceitos e abordagens que diferem do atual debate acerca da Música e sua aprendizagem no âmbito escolar, evoco estudos multiculturais no intuito de pensarmos quais possibilidades, caminhos e reconfigurações para o campo da educação musical. Não significa que o que abordo aqui é uma ação totalizadora para o exercício do ensino e da aprendizagem da Música na escola, mas sim para repensarmos outras maneiras e com constantes diálogos diante das demandas da sociedade contemporânea.

Entre o que é definido conceitualmente por multicultural, multiculturalidade e multiculturalismo e intercultural, interculturalidade e interculturalismos, exponho alguns ideias buscando interfaces para embasar uma proposta de aprendizagem musical que parta da abertura de possibilidades e de escolhas curriculares que promovam contínuos encontros com as vivências, sotaques e discursos culturais dos educandos, visando 
construir com eles a propostas para um exercício de construção de um mundo plural e humanizado, com respeito e aceitação do outro, que possui valores, angústias, desejos e crenças.

Inicio essa construção partindo dos conceitos estabelecidos do multiculturalismo focando na interculturalidade. Existem várias correntes de pesquisadores que pautam e identificam na sociedade e no movimento dela, a relação ora aberta, ora fechada desses conceitos que aqui serão apresentados e discutidos, na busca de uma visão plural e minimamente agregada de possibilidades para promoção de um mundo mais justo e igual de direitos, porém, ressaltando as diferenças, pois ao "multiculturalismo não interessa à sociedade como um todo, e sim a certos grupos sociais que, de uma forma ou de outra, são excluídos dos centros de decisão por questões econômicas e, sobretudo, por questões culturais" (GONÇALVES; SILVA, 2013, p. 29).

Candau (2008, p. 50) defende três tipos de modelos, "o multiculturalismo assimilacionista, o multiculturalismo diferencialista ou monoculturalismo plural e o multiculturalismo interativo, também denominado interculturalidade". No decorrer do texto utilizarei das nomenclaturas destacadas a fim de clarear as ideias de cada modelo.

Pauto nossa discussão sobre três tipos de multiculturalismo apontados por Candau (2008) aventurando-me na possibilidade de observar e propor algumas maneiras de se pensar o papel da música na Educação Básica como um norte composto por diferentes processos de ensino com iguais direitos de aprendizagem, buscando um movimento linear, tentando quebrar, esmiuçar e esquartejar, alguns paradigmas hoje tão enraizados e marcados pela intolerância, pelo preconceito, pela discriminação, por estereótipos pré-condicionados e estabelecidos e pela excl. usão de mundos e diferentes culturas.

Vamos ao primeiro modelo apontado por Candau (2008, p. 50), o assimilacionista. Para a autora, essa abordagem na condição de sociedade está definida por direitos não igualitários, ou seja:

Nessa sociedade multicultural todos não têm as mesmas oportunidades; não existe igualdade de oportunidades. Há grupos, como os indígenas, negros, homossexuais, pessoas oriundas de determinadas regiões geográficas do próprio país ou de outros países e de classes populares e/ou com baixos níveis de escolarização, que não tem o mesmo acesso a determinados serviços, bens, direitos fundamentais que têm outros grupos sociais, em geral de classe média 
ou alta, brancos e com altos níveis de escolarização (CANDAU, 2008, p. 50).

Vemos aqui pautado nesse significado posto pela autora, um movimento excludente que não contempla a ideia de diversidade humana e cultural existente no mundo. Talvez seja pela Educação o caminho para desconstrução dessa identidade arbitrária aos muitos direitos humanos. Talvez seja pelo que defendemos aqui sobre ensino de Música uma condição de respeito ao outro e as suas condições de diferença. A meu ver, somente por uma Educação humanizadora e emancipatória, esse modelo pode sair de uma vez por todas do pensamento arcaico do empoderamento social conservador que tanto habita as escolas e os currículos que muitas delas defendem como proposição pedagógica.

Presenciamos na contemporaneidade genocídios culturais que são exemplos claros de uma matança e simbólica de muitos outros tantos mundos, não colocados no bojo da igualdade de direitos, postos sob a ideia e ação de exclusão, de intolerância e de desigualdade. Pensando em um processo de uma Educação emancipatória, de ensino e de pedagogia, indagamos (a) será que necessitamos realmente assassinar diferentes culturas em detrimento de uma única e hegemônica forma de fazer cultura? (b) será talvez que a escola não esteja fazendo a mesma coisa dentro de seus muros? (c) será que nós particularmente professores não impomos em nossa forma de ensinar nossas visões de mundo sem diálogo com o outro? Candau (2008) responde essas perguntas sinalizando que

no caso da educação, promove-se uma política de universalização da escolarização, todos são chamados a participar do sistema escolar, mas sem que se coloque em questão o caráter monocultural presente na sua dinâmica, tanto no que se refere aos conteúdos do currículo quanto às relações entre diferentes atores, às estratégias utilizadas nas salas de aula, aos valores privilegiados etc. Simplesmente os que não tinham acesso a esses bens e a essas instituições são incluídos nelas de tal maneira como elas são. Essa posição defende o projeto de construir uma cultura comum e, em nome dele, deslegitima dialetos, saberes, línguas, crenças, valores "diferentes", pertencentes aos grupos subordinados, considerados inferiores explícita ou implicitamente (2008, p. 50). 
Ou seja, talvez, hoje nos distintos espaços de educação, sejam eles escolarizados ou não escolarizados, é necessário ter como meta a concepção de desenvolvimento humano e não na exclusão de direitos humanos. Talvez, cada vez mais e explicitamente dado pela mídia a favor dos direitos humanos, percebemos hoje mais do que nunca, que estamos a caminho de uma barbárie, de uma carnificina e de um holocausto sociocultural.

A crítica a esse modelo que coloco em pauta trata do movimento perverso em que a sociedade, em termos políticos, econômicos, sociais e culturais, está caminhando e demarcando seu espaço na construção de um mundo cruel em busca de uma única forma de pensar, agir e ser, desnudando e descaracterizando o outro afirmando que ele não é bem vindo, na tal sociedade, com múltiplos privilégios, com "condições geradas pela imbatível concentração de renda e insuperável segregação e exploração humanas" (FILHO, 2010, p. 74).

Outro signo apontado pela autora é o diferencialista. Esse modelo está intrinsicamente ligado à concepção assimilacionista na composição da autora, pois trata da estagnada ação de um determinado grupo social que reafirma uma não igualdade a mundo na relação de direitos, mas de condicionamentos de um único e dado mundo, ou seja, esse modelo

parte da afirmação de que, quando se enfatiza a assimilação, se termina por negar a diferença ou por silenciá-la. Propõe colocar a ênfase no reconhecimento da diferença e, para garantir a expressão das diferentes identidades culturais presentes num determinado contexto, garantir espaços em que estas possam expressar. Afirma-se que somente assim os diferentes grupos socioculturais poderão manter suas matrizes culturais de base (CANDAU, 2008, p.51).

Tal modelo por sua vez, também marca posicionamento sobre a massificação em um mesmo bloco "gavetístico" mundos e indivíduos que têm em suas vivências, outra concepção talvez diferente daquela então estabelecida, não cabendo nessa pequena gaveta, sendo então, imprensado a caber.

Modelo que talvez venha imprensando e esmagando na parede e passando por cima com um rolo compressor nas outras formas de viver culturalmente, corroborando integralmente e violentamente para um verdadeiro apartheid. Aí, vemos 
demasiadamente a destruição de muitas culturas, marcada pelo intolerável modelo de unificado de uma sociedade sem ao menos possibilitar a ideia da diferença existente de indivíduos e igualdade de direitos, como é destacado pela autora quando se refere que

hoje não é possível se trabalhar questões relacionadas à igualdade sem incluir a questão da diferença, nem se pode abordar a questão da diferença dissociada da afirmação da igualdade. De fato, a igualdade não está oposta à diferença, e sim à desigualdade, e diferença não se opõe à igualdade e sim a padronização, à produção em série, à uniformização (CANDAU, 2012, p. 239).

Concordo com a autora que em todos os momentos, sejam eles no campo da aprendizagem musical como das outras áreas do conhecimento ou nos mais simples momentos da relação com o outro em sociedade aprendemos e, devamos ter a ciência, discernimento e consciência que somos diferentes reforçando a ideia de cor, credo, crenças e valores, porém iguais, em direitos que permeiam o social, econômico, político e educacional como um todo.

Necessitamos repensar propostas e caminhos para que a Música no seu processo de aprendizagem escolar não seja colocada e calcada pedagogicamente nos moldes predominantemente hegemônicos, ou seja, que possamos propor um projeto educativo emancipatório com justiça social e cognitiva, fora das concepções dos projetos eurocêntricos dominantes, ressaltando uma educação musical

que seja capaz de romper com o formato disciplinar definido para as escolas do séculos XIX e que ainda hoje fragmenta o saber musical em gavetas estanques de formação. Uma educação musical que ouça a sonoridade humana a partir das múltiplas vozes que cantam o mundo e que, cada uma a seu modo, encontra formas de organização distintas, valores e buscas estéticas variadas, estratégias e caminhos de formação diversificados (QUEIROZ, 2015, p. 207).

Dentro dessa perspectiva de rompermos com os cânones historicamente constituídos por concepções hegemônicas, a última abordagem e a qual proponho fundamentar abordagens em educação musical é o da interculturalidade. Caminho este de respeito pelo plural, interação de cultural, com compreensão do outro valorizando principalmente seu mundo, suas crenças e culturas, como um grande coral em que 
muitas vozes, diferentes tessituras, baixo, contraltos, tenores, sopranos, afinados ou não, são convidados a exercer sua voz.

Candau (2008, p. 51) aponta três características que delineiam essa perspectiva. A primeira se dá na "promoção deliberada da inter-relação entre diferentes grupos culturais presentes em uma determinada sociedade." Assim, retrata a segunda característica sinalizando que "cada cultural tem suas raízes, sendo raízes históricas e dinâmicas." Assim, elas "não fixam as pessoas em determinado padrão cultural" A terceira e última característica está em consonância com o processo de hibridização. A autora destaca que tal característica "está constituída pela afirmação de que nas sociedades em que vivemos os processos de hibridização cultural são intensos e mobilizadores da construção de identidades abertas, em construção permanente, o que supõe que culturas não são puras”.

Sobre o hibridismo cultural, podemos levar em conta que é uma visão política. Ou seja, são relações antagônicas resultantes de negociações culturais, diálogo com o outro, no qual a identidade cultural em nós está em constante reformulação, ressignificação, reconstrução e assimilação no qual, nós indivíduos, podemos nos permitir revisar e reformular novas formas de ver o mundo, aceitar e talvez mudar nossas concepções de crenças e valores a partir do choque cultural dado na relação com o mundo e com o outro (BURKE, 2003). Uma educação musical pautada nesse sentido é uma ação pedagógica que contempla distintas epistemologias e com constante diálogo com "pluralismo de idas e práticas educativas, que contempla as diferenças na promoção da igualdade e que promova e fortaleça a diversidade dos humanos e de suas formas de ser, estar e se expressar no mundo" (QUEIROZ, 2015, p. 199).

Dadas às características representadas de forma clara e em consonância com o campo da educação musical, corroboro com a definição de interculturalidade proposta por Candau (2008), no sentido de repensarmos proposições educacionais que venham tecer conversas com a contemporaneidade no sentido de observar as tensões entre igualdade, identidade e diferenças que permeiam os espaços educacionais. Nesse sentido, é de suma importância que nós educadores, repensemos sempre o currículo como potência, como espaço para a construção de novos saberes, como campo de produção de novos sentidos e significados, no intuito de sobrepor as ordens dominantes para ampliar ao 
máximo de consciência possível a incompletude de todas as culturas, entendendo que esse procedimento abre possibilidades ao diálogo intercultural e pode contribuir para a superação dos epistemicídios perpetrados pela modernidade eurocêntrica contra outras culturas e outros modos de conhecer o mundo (OLIVEIRA, 2009, p. 116).

Diante desse propósito que os estudos pós-coloniais² (BABHA, 2013; HALL, 2015 e CANCLINI, 2015) sinalizam acerca dos epistemicídios que as culturas dominantes vêm causando ao longo dos anos, talvez a ideia de multiculturalismos intercultural definido a partir da voz de Catherine Wlash (2001), pode ser um meio para um pensamento de uma nova epistême em educação musical escolar vista como uma ação de promoção de sentidos em meio aos processos de ensino e aprendizagem musical. Assim, a autora aponta a interculturalidade como

\begin{abstract}
um processo dinâmico e permanente de relação, comunicação e aprendizagem entre culturas em condições de respeito, legitimidade mútua, simetria e igualdade. Um intercâmbio que se constrói entre pessoa, com conhecimentos, saberes e práticas culturalmente diferentes, buscando desenvolver um novo sentido entre elas na sua diferença. Um espaço de negociação e de tradução onde as desigualdades sociais, econômicas e políticas, e as relações e os conflitos de poder da sociedade não são mantidos ocultos e sim reconhecidos e confrontados. Uma tarefa social e política que interpela o conjunto da sociedade, que parte de práticas e ações sociais concretas e conscientes e tenta criar modos de responsabilidade e solidariedade (WLASH, 2001, p. 10-11 apud CANDAU, 2008, p. 52).
\end{abstract}

O importante de pensarmos a interculturalidade, no seio dos distintos processos de educação musical, é que, por meio dessa prática, podemos pensar em um mundo mais justo, democrático e em constante à contemporaneidade. Pensada como tempo presente, compreendido de forma desfragmentada e permeada pela conjuntura de elementos que, imbricados no âmbito social, estabelece a complexa rede de relações, trocas e

\footnotetext{
${ }^{2}$ Os estudos que tratam do conceito de Pós-colonialismo abordam os efeitos que as nações colonizadoras deixaram na cultura dos países colonizados. Dento de uma abordagem conceitual estes e outros autores buscam analisar como, espaços, pessoas, conceitos, ideias foram construídas em âmbito de subalternidade em relação às hegemônicas culturas tidas como superiores e desenvolvidas. Entre diversos aspectos, são analisados campos como política, filosofia e artes.
} 
ressignificações de situações até então postas em local definido e hoje confrontado pela composição de novos saberes, conhecimentos, formas de comunicação e acesso, entre outros aspectos, que fazem do nosso tempo, algo significativo, singular e plural ao mesmo tempo e, com tensões dadas a partir do diálogo que estabelece no coletivo na sua complexa rede constituída entre o "eu”, o “outro" e o "mundo" (QUEIROZ, 2013; 2015).

É interessante destacar que esse percurso de inter-relacionar diferentes culturas abre caminhos para enxergar a si mesmo, o outro e o mundo de outra forma, abrindo possibilidade para ressignificação em prol da desconstrução e da desterritorialização de pensamentos e ações, que talvez estejam corroborando cidadãos comuns, pessoas com atitudes empoderadas de visões errôneas em relação ao outro, ou seja, o que se pensa de uma educação musical com cunho intercultural está no âmbito de uma

proposição de diálogos e interações entre saberes diferentes culturas musicais, não para buscar homogeneidade, por vezes delineada no cenário das políticas neoliberais de promoção à educação e à diversidade, mas para promover a diferença, o conflito e a singularidade humana e cultural. Uma educação musical intercultural evoca a necessidade de uma revisão epistemológica sobre o que a música é e sobre o que educar musicalmente quer dizer e, além disso, reivindica novas concepções, diretrizes e estratégias (QUEIROZ, 2015, p. 207).

Falando especificamente de ensino e a aprendizagem de Música e da sua contribuição na luta democrática dos verdadeiros direitos humanos, talvez esse ensino pudesse ser dentro da mais democrática arte por adotar a ideia do coletivo no seu fazer. Talvez os educadores musicais pudessem escolher, por alguma razão ou causa ter em mente o discernimento de que a Educação está aí para contribuir com o outro para um projeto emancipatório e não epistemicída. Que educação musical não é para ficar ensinando 5 linhas e 4 espaços, educação musical tem o seu objetivo centro no humano e na sua relação com o conhecimento e com o saber, no qual o projeto emancipatório educativo perpasse pelos territórios que habitam o ensino a aprendizagem musical no cotidiano da sala de aula. 


\section{Diversidade Cultural e Educação Musical na Educação Básica}

A proposta de desenvolvermos uma educação musical que comtemplo e dialogue com a diversidade cultural pode ser um exercício pedagógico do cotidiano escolar. Cotidiano esse entendido como processos de trocas, intercâmbios e fluxos contínuos de novos conhecimentos e saberes. Música na escola com ampla diversidade sonora e ampliação de novas concepções estéticas que possam tecer encontros permanentes com os diferentes repertórios que são produzidos por distintos grupos em plurais situações.

É importante termos em mente que a escola é local de conflito de conhecimentos proporcionados pelos seus indivíduos que nela circulam, é espaço de ampliação do saber e lugar de tensões que podem servir de elemento pedagógico para constituir um currículo que contemple concepções e ações para viver e interferir no mundo em que (com) vivem com o outro.

Com a construção de um currículo que tenha suas bases construídas em epistemologias que dialogue com a contemporaneidade e com os saberes e conhecimentos individuais e coletivos dos atores que compõem o espaço escolar, processo pedagógico musical pode ter diretamente e/ou indiretamente a diversidade cultural contemplada na ação educativa emancipatória.

É de sua importância que a escola proporcione ao indivíduo a ampliação dos seus saberes a partir do que ele tem como material cultural. No âmbito da educação musical podemos trabalhar com investigações, com construções cartográficas, visando obter do aluno quais são os seus sotaques, usos e consumos musicais. A partir desse trabalho praticado podemos apresentar outros mundos musicais no intuito de ampliar o rol de possibilidades e encontros sonoros. É importante que esse trabalho seja mediado por distintas formas de observar as diferentes manifestações onde essas músicas são produzidas para não cometermos epistemicídios de uma prática pedagógica musical que pode ser aberta ao tecer encontros com e para os indivíduos que terão acessos a outras possibilidades de materiais sonoros.

Queiroz (2011, p.20) propõe essa ação sob duas vertentes centrais, a primeira vertente aponta pelo educador musical parte do "universo musical trazido pelos alunos", ou seja, como, de que maneira e modo, podemos valorizar e inserir no currículo e nos processos didáticos os sotaques musicais dos atores inseridos no processo de ensino e 
aprendizagem entendendo que essa proposição pode ter de alguma forma e/ou modo seu lugar efetivo na prática pedagógica no cotidiano escolar. Sobre essa primeira vertente o autor ainda destaca que "essas músicas além de terem significados culturais para os estudantes, possibilitam diversos trabalhos relacionados à linguagem musical, explorando aspectos como: sonoridades e timbres dos instrumentos, formas de cantar, padrões rítmicos e estruturas melódicas”.

A segunda vertente "está relacionada à inserção, na prática escolar de músicas de diferentes contextos culturais, visando à ampliação e/ou transformação do universo musical dos alunos." Ou seja, a proposição aqui dada está em consonância com uma relação que se estabelece na ação pedagógica como ato emancipatório por meio dos saberes e dos conhecimentos que se dão na construção de um currículo que contemplará as distintas vozes dos indivíduos dados por um convite de coparticipação na construção coletiva ética e estética para uma ampliação do seu universo musical.

\footnotetext{
Nessa categoria podem ser incluídas músicas locais, que não tem veiculação midiática e que, muitas vezes, são desconhecidas pelos estudantes; músicas singulares de outras cidades, estados, regiões, países etc. O objetivo não é simplesmente, levar para a escola um amontoado de expressões musicais desvinculadas de suas realidades socais, mas sim, possibilitar que os alunos reconheçam vários "sotaques", para que, assim, possam reconhecer melhor, inclusive, seu próprio "sotaque" e, a partir daí, a seu critério, (re)significá-lo, ampliálo e/ou transformá-lo (QUEIROZ, 2011, p. 20).
}

Tais vertentes podem corroborar para um momento importante da história da educação musical brasileira, que hoje repensa e reconsidera com responsabilidade social e ética uma formação humana a partir do contato com a diversidade cultural, com as distintas identidades sonoras musicais do mundo e seus universos onde são produzidas entendendo que "reconhecer que a dominação de algumas culturas musicais sobre outras não se dá ao acaso, mas é resultado de determinantes culturais enraizadas na sociedade e na cultura e vinculadas às diferentes dimensões econômicas, raciais, éticas, de gênero, de religião" (QUEIROZ, 2015, 202).

Nesse propósito repensar o lugar da diversidade cultural nas ações pedagógicas musicais de ensino e aprendizagem perpassam por um currículo que contemple uma visão de mundo mais aberta, flexível e de respeito com o outro e em contínuas conversas com a "pluralidade de identidades que caracterizam os grupos e as sociedades que 
compõem a humanidade" garantindo sempre nos processos pedagógicos musicais "uma interação harmoniosa entre pessoas e grupos com identidades culturais a um só tempo plurais, variadas e dinâmicas" (UNESCO, 2002).

Retomo a voz de Candau (2008), buscando algumas maneiras para pensar a diversidade cultural, a interculturalidade com foco na educação musical trazendo para a discussão alguns caminhos que possivelmente possam nos dar pistas para uma ação emancipatória em diálogo com as tensões que habitam os espaços educacionais, marcados pela crueldade intensificadora da exclusão social existente no mundo.

O primeiro ponto que a docente aponta está na desconstrução "de estereótipos e pré-conceitos que povoam nossos imaginários individuais e sociais em relação aos diferentes grupos socioculturais (...)” e a desestabilização do monoculturalismo e etnocentrismo de informações e dos saberes, apontando para a "universalidade dos conhecimentos, valores e práticas que configuram as ações educativas” (p.53). Pensando musicalmente dentre de uma perspectiva intercultural a diversidade cultural tem grande importância na esfera de repensarmos outras possibilidades e encontros epistemológicos diante de universo musical que o mundo oferece. Ou seja, repensar as formas de ver e fazer música é preponderante nesse processo a partir dos encontros com as músicas do mundo. Músicas essas que possuem outras formas de organização que não são aquelas estabelecidas pelos cânones estilísticos europeus dominantes. Músicas estas que utilizam de outros materiais, outros sentidos de produção e outros padrões de escrita e execução.

A segunda propõe a ideia de articulação entre igualdade de direitos e diferença de indivíduos. Ou seja, se dá na garantia de "diferentes sujeitos socioculturais se reconheça, assegurando, assim, que a igualdade se explicite nas diferenças que são assumidas como referência comum, rompendo dessa forma, com o caráter monocultural" (p. 53). Podemos pensar em educação musical articulando os saberes e os conhecimentos propostos para o dia a dia da sala de aula com esferas que discutam o reconhecimento das distintas culturas musicais trazendo para o rol de apresentação dos distintos repertórios discussões que contenham diálogo com as questões dos direitos humanos que na contemporaneidade tem sido pauta de debate no campo da Educação. O terceiro ponto trata do resgate de "identidades culturais tanto no nível pessoal como coletivo". Acredito este ponto ser um ponto mais importante, sem menos prezar cada 
um dos pontos apontados pela autora, mas seja este talvez, uma forma de ser e estar no mundo, pensando a interculturalidade nos distintos processos de educação, sendo importante "esse resgate das histórias de vida, tanto pessoais quanto coletivas, e que elas possam ser contadas, narradas, reconhecidas, valorizadas como parte de processo educacional" (p. 53). Ou seja, em um país tão grande e diversificado como o Brasil que produz distintas manifestações culturais como a Catira, o Jongo, o Coco, o Siriri, o Cururu, o Ijexá, o Carimbó, o Samba, com distintos festejos e manifestações populares ficamos preocupados em inserir em nossos processos de aprendizagem musical os cânones musicais "norte americanizados" e "europeizados", deslegitimando e desconsiderando toda uma cultura latinoamericana do qual nós brasileiros somos. Nesse propósito é interessante que

\footnotetext{
se opere um conceito dinâmico e histórico de cultura capaz de integrar as raízes históricas e as novas configurações, evitando uma visão das culturas como universos fechados e em uma busca do "puro", do "autêntico" do "genuíno", como essência preestabelecida em um dado que não está em contínuo movimento. Esse aspecto relaciona-se também ao reconhecimento e à promoção do diálogo entre os diferentes saberes, conhecimentos e práticas dos diferentes grupos culturais (CANDAU, 2008. p. 53 - 54).
}

Acredito que, por no centro do currículo e da ação didática o diálogo nossas vivências, nossas culturas, nossos valores, bem como aquilo que é importante para nós e para o outro, é realmente de suma importância em um processo de educação musical, diversificadamente plural, aberto a ressignificações e a reconsiderações. É um desafio para ser trilhado todos os dias na escola em outros espaços educativos, na relação mútua com os indivíduos, observando as distintas expressões socioculturais que adentram nos processos de formação humana e o exercício da cidadania. Cabe então, de alguma maneira, proporcionar experiências significativas, reinventando experiências do cotidiano a partir de um processo de educação imbuída de aspectos culturais advindos da convivência em sociedade, trazendo significativas contribuições para o processo educacional permeado por justiça social e cognitiva, favorecendo a ampliação, a aceitação e o respeito ao universo cultural uns dos outros.

$\mathrm{O}$ quarto e último eixo aponta a promoção da experiência. De acordo com Candau (2008), essa proposta visa promover "experiências de interação sistemática com 
os outros, para sermos capazes de relativizar nossa própria maneira de situar-nos diante do mundo e atribuir-lhe sentido, é necessário que experimentemos uma intensa interação com diferentes modos de viver e expressar-se” (p. 54). Com esse propósito, proponho pensar a aprendizagem musical no âmbito dos significados que são engendrados em nossas relações humanas, nos processos de formação decorrentes dos fenômenos musicais que estabelecem na vida dos indivíduos, e não preso aos padrões estético-sonoros e performáticos propriamente e ditados por um ensino modernista e metafísico. O que se propõe como objetivo da educação musical é o HUMANO, na relação mais significativa e singular com a MÚSICA, como aponta Queiroz (2013) está orquestrado para o indivíduo

\begin{abstract}
adquirir conhecimento e habilidade que lhe permitam compreender e praticas a música a partir dos seus parâmetros sonoros dos diversos aspectos que configuram esse fenômeno como expressão artística, humana e cultural; desenvolver-se técnica intelectual e cognitiva para que possa se expressar musicalmente por meio de códigos específicos da linguagem musical; ter acesso, e vivenciar, produções musicais de representativo valor para as culturas do mundo, compreendendo a música como agregadora de características, valores e significados diversos, que tem os seus atributos vinculados aos distintos meios sociais em que o fenômeno musical é produzido; lidar com o seu universo social, participando criticamente da seleção, prática e valoração das músicas que constituem o seu entorno cultural; praticar e vivenciar uma ampla diversidade de músicas, entendendo as bases estruturais de fenômeno sonoro, mas também os significados que estabelece com os múltiplos contextos cultuais (p. 116).
\end{abstract}

Por mais que esses objetivos propostos pelo educador musical sejam cruciais e fundamentais para a aprendizagem musical dos estudantes é importante também que sejam elencados elementos que o empoderem ${ }^{3}$ o indivíduo para viver na contemporaneidade diante das atrocidades e assassinatos sociais do mundo, tornando-o apto se inserir nesse universo, modificando e combatendo o holocausto presente na ação com o outro. Que se estabeleça um elo entre a diversidade cultural, o multiculturalismo intercultural e a educação musical visando realizar jogos contínuos entre vozes que ocupam planos culturais distintos, propondo no processo de aprendizagem musical na

\footnotetext{
3 Termo utilizado pelo Movimento LGBTI, Negro, das Feministas, dentre outros. Termo também cunhado da literatura das Ciências Sociais.
} 
escola o ato emancipatório, com justiça social e cognitiva nas ações didáticas, com responsabilidade social ao pensar o currículo na condução de novas formas de conceber discursos, ideias e formas de agir para uma promoção da igualdade de direitos sociais, econômicos, culturais e educacionais trazendo sempre a ideia de que somos diferentes com e identidades diversificadas.

\section{Considerações finais}

Sobre algumas ideias finais, aponto que a discussão não se encerra por aqui, a discussão tem grande arcabouço para diálogo, entendendo também que aqui foram esboçadas algumas ideias, reflexões e pensamentos acerca de uma educação musical intercultural orquestrada por uma diversidade cultura. Penso que, a aprendizagem musical, na sua construção de saberes com o conhecimento individual e os coletivos pode ser norteada por pluralidade de concepções e ações que mantenham contínuo diálogo abarcando a diversidade humana que circula nos espaços escolares. Que nesses processos de aprendizagem musical seja proporcionada a construção de um currículo que possa incluir diferentes visões de mundo, com valorizações e inserções das distintas identidades e sotaques musicais dos indivíduos que constroem coletivamente o espaço escolar.

Que o ensino de Música, em diálogo com a contemporaneidade marcado pela Cultura e pela Educação, que se reinventa no cotidiano no seu singelo e mais puro acontecer, promova a interface com temas transversais, hoje tão importantes no dia a dia, na adoção de uma visão mais ampla e aberta das necessidades e emergentes demandas na luta contra arquétipos anti-humanistas, na luta pela democracia, pela igualdade de direitos e pelo respeito à diferença, visando romper e caminhar em outro lócus no qual a Música possa ser

um fenômeno diversificado e que suas formas de organização e significado the conferem identidades singulares em cada contexto cultural tem nos alertado para a necessidade de rompermos com hegemônicas estéticas, com perspectivas ontológicas e epistemológicas baseadas em modelos de criação e prática musical unilaterais, com histórias lineares do fenômeno musical e com padrões educacionais configurados exclusivamente a partir dos modelos voltados para 
repertórios canônicos dominantes nas instituições (QUEIROZ, 2015, 198).

Talvez na aventura da discussão dos diferentes pontos de vista postos em conflito no bojo da conversa do "eu" com o "outro" e "nós" com o Mundo, seja valorizado o entendimento de que nenhum ponto de vista é melhor ou majoritário do que o ponto de vista do outro, que nenhum caminho apontado seja colocado a ponto de se decidir por certo ou errado, bom ou ruim, feio ou bonito, e sim, a diversidade de muitas ideias e visões de mundo sejam alicerce para o processo de ensino e aprendizagem musical na escola.

Processo esse, não epistemicída mas com respeito à diversidade e a pluralidade musical do mundo, não com um amontoado de músicas desconectadas com uma real proposta de projeto educativo emancipatório na a ampliação do conhecimento de si, do outro e do mundo, valorizando o seu discurso musical em primeira instância, propondo a partir daí, um olhar mais significativo, singular e com o devido sentido que Música É.

\section{Referências}

BABHA, Homi K., O local da cultura; tradução de Myriam Ávila, Eliane Lourenço de Lima Reis, Gláucia Renate Gonçalves. - 2. ed. - Belo Horizonte: Editora UFMG, 2013.

CANCLINE, Néstor Garcia. Culturas Híbridas: Estratégias para entrar e sair da Modernidade; tradução de Heloísa Pessa Cintrão, Ana Regina Lessa. - 4. ed. - São Paulo: Editora da Universidade de São Paulo, 2015.

CANDAU, Vera Maria. Direitos humanos, educação e interculturalidade: as tensões entre igualdade e diferença. In: Revista Brasileira de Educação v. 13 n. 37 jan./abr. 2008.

Diferenças culturais, interculturalidade e educação em direitos humanos. In:

Educ. Soc., Campinas, V. 33, n.118, p. 235-250, jan./mar. 2012. 
FIGUEIREDO, Sérgio Luiz Ferreira de. Educação Musical Escolar. In: Textos complementares à série Educação Musical Escolar com veiculação no programa Salto para o Futuro - TV Escola de 27/06/2011 a 01/07/2011.

FILHO. Aldo Victório. Fulgurações periferizadas: produção estética, epistemológica e acontecimento juvenil para além da escola. In: Práticas Cotidianas e emancipação social: do invisível ao possível. Inês Barbosa de Oliveira (org.). - Petrópolis: DP et al., 2010.

FONTERRADA, Marisa Trench de Oliveira. De Tramas e Fios: Um Ensaio Sobre Música e Educação. São Paulo: Ed. UNESP, 2008.

GONÇALVES, Luiz Alberto Oliveira; SILVA, Petrolina Beatriz Gonçalves e. O jogo das diferenças: o multiculturalismo e seus contextos. - 5. ed. - Belo Horizonte: Autêntica Editora, 2013.

HALL, Stuart. A identidade cultural na pós-modernidade, tradução de Tomaz Tadeu da Silva e Guacira Lopes Louro. - 12. ed. - Rio de Janeiro: Lamparina, 2015.

OLIVEIRA, Inês Barbosa de. Boaventura Eં a Educação. - 2. ed. - Belo Horizonte: Autêntica, 2008.

PEREIRA, Luis Felipe Radicetti. Um movimento na bistória da educação musical no Brasil: Uma Análise da Campanha pela Lei 11.769/2008. 2010. Dissertação (Mestrado em Música) - Programa de Pós-Graduação em Música, Centro de Letras e Artes, Universidade Federal do Estado do Rio de Janeiro.

QUEIROZ, Luis Ricardo Silva. Diversidade musical e ensino de música. Educação Musical Escolar, Rio de Janeiro, ano 21, n. 8, p. 17-23, jun. 2011. Textos complementares à série Educação Musical Escolar com veiculação no programa Salto para o Futuro/TV Escola de 27/06/2011 a 01/07/2011.

QEUIROZ. Luis Ricardo Silva. MARINHO, Vanildo Mousinho. Educação musical nas escolas de educação básica: caminhos possíveis para a atuação de professores não especialistas. Revista da ABEM, Porto Alegre, V.17, p. 69-76, 2009

Diversidade musical e ensino de música. In: Textos complementares à série Educação Musicais Escolar com veiculação no programa Salto para o Futuro - TV Escola de 27/06/2011 a 01/07/2011. 
. Escola, cultura, diversidade e educação musical: diálogos da contemporaneidade. In: InterMeio. Revita do Programa de Pós-Gradauação em Educação, Campo Grande, MS, v. 19, n. 37, p. 95-124, jan/jun. 2013.

. Há diversidade(s) em música: reflexões para uma educação musical intercultural. In: Música e Educação. (org.) Helena Lopes da Sailva e José Antônio Baêta Zille. - Barbacena: EdUEMG, 2015. - (Série Diálogos com o Som. Ensaios, v.2).

SANTOS, Boaventura Souza. Para uma pedagogia do conflito. In: Novos mapas culturais, novas perspectivas educacionais. Luiz Heron Silva, José Clovis dos Santos, Edmilson do Santos. Porto Alegre: Sulina, 1996.

UNESCO. Declaração Universal sobre a Diversidade Cultural. 2002. Disponível em: < http://unesdoc.unesco.org/images/0012/001271/127160por.pdf>. Acesso em: 05 novembro. 2016. 